\title{
Theoretical density functional study of gas-phase tautomerization and acidity of 5-methylhydantoin and its thio derivatives
}

\author{
Zaki Sulieman Safi \\ Department of Chemistry, Faculty of Science, Al Azhar University-Gaza, 1277, Gaza, Palestine \\ *Corresponding author at: Department of Chemistry, Faculty of Science, Al Azhar University-Gaza, 1277, Gaza, Palestine. Tel.: +970.8.2824010; fax: +970.8.2823180. \\ E-mail address: z.safi@alazhar-gaza.edu (Z.S. Safi).
}

\section{ARTICLE INFORMATION}

\section{Received: 22 May 2012}

Received in revised form: 19 July 2012

Accepted: 21 July 2012

Online: 30 September 2012

\section{KEYWORDS}

DFT

B3LYP

Acidity

Deprotonation

Tautomerization

5-Methylhydantoin

\begin{abstract}
Tautomerization and acidities of various 5-methylhydantoins and their thio derivatives were predicted using Density Functional Theory (DFT). The functional used was B3LYP and the basis set for all atoms was $6-311+(d, p)$. Single point energy computations were performed at the $6-311+G(2 d f, 2 p)$ basis set. The relative stabilities of the different tautomers of the 2,4dioxo, 2-thio-4-oxo, 4-thio-2-oxo and 2,4-dithio derivatives of the deprotonated 5methylhydantoin have been studied. In all cases, the most stable deprotonated conformers are the oxo-thione, the dioxo or the dithio. As for the neutral and the protonated 5methylhydantoin-thio derivatives, the tautomerization activation barriers are high enough as to conclude that the oxo-thione structures should be found in the gas phase. It was revealed that the ring-nitrogen atom at position 3 (N3) is more acidic than that at position 1 (N1), hence 5-methylhydantoin thio derivatives in the gas phase are an N3-acid. It has been found that the 2,4-dithio species is the most acidic compound among all the investigated compounds. The acidity values were found to be 343 (2040), 337 (2S40), 336 (204S) and $332 \mathrm{kcal} / \mathrm{mol}(\mathbf{2 S 4 S})$.
\end{abstract}

\section{Introduction}

and rotaomers, the energy barriers of 1,3- $\mathrm{H}$ migration from the most sable oxo-thione, dioxo and dithio forms to the most stable enolic structures, to investigate the enolioztion mechanism when the oxygen atom is substituted by a bulkier atom such as sulfur and to investigate the possible catalytic role of the deprotonation process of the different imidic groups on the tautomerization process. The second one is to determine the gas-phase acidity of the acidic centers of the neutral species and compare them with that of the radical ones at different basis sets. The molecules considered in this theoretical survey are 5-methyl-2,4-dioxo imidazolidine (2040), 5-methyl-2-oxo4-thio imidazolidine (204S), 5-methyl-2-thio-4-oxo imidazoleidine (2S40), and 5-methyl-2,4-dithio imidazolidine (2S4S) (Scheme 1).

\section{Computational details}

The geometries of the species under considerations were fully optimized with the aid of the Gaussian 09 set of programs [19], using the hybrid density functional theory (DFT) [20,21] at the B3LYP level [22-24] combined with the polarized triple split valence $6-311+G(d, p)$ basis functions. The relative B3LYP energies are often in excellent agreement with high-level $a b$ initio results $[18,25,26]$. Harmonic vibrational frequencies were calculated at the same level of theory to identify the local minima and transition states (TS) and to estimate the corresponding ZPE. Final energies were obtained in singlepoint calculations carried out at the B3LYP/6-311+G(2df,2p) level. The corresponding relative energies were evaluated with inclusion of the corresponding ZPE corrections scaled by a factor of 0.9806 [27] and the thermal correction of energies.
In continuation with our previous work on tautomeization [17] and protonation [18] of 5-methylhydantoin and its thio derivatives, the present paper is reporting a systematic theoretical study with the following two objectives. The first one is to study the gas-phase relative stabilities of tautomers 


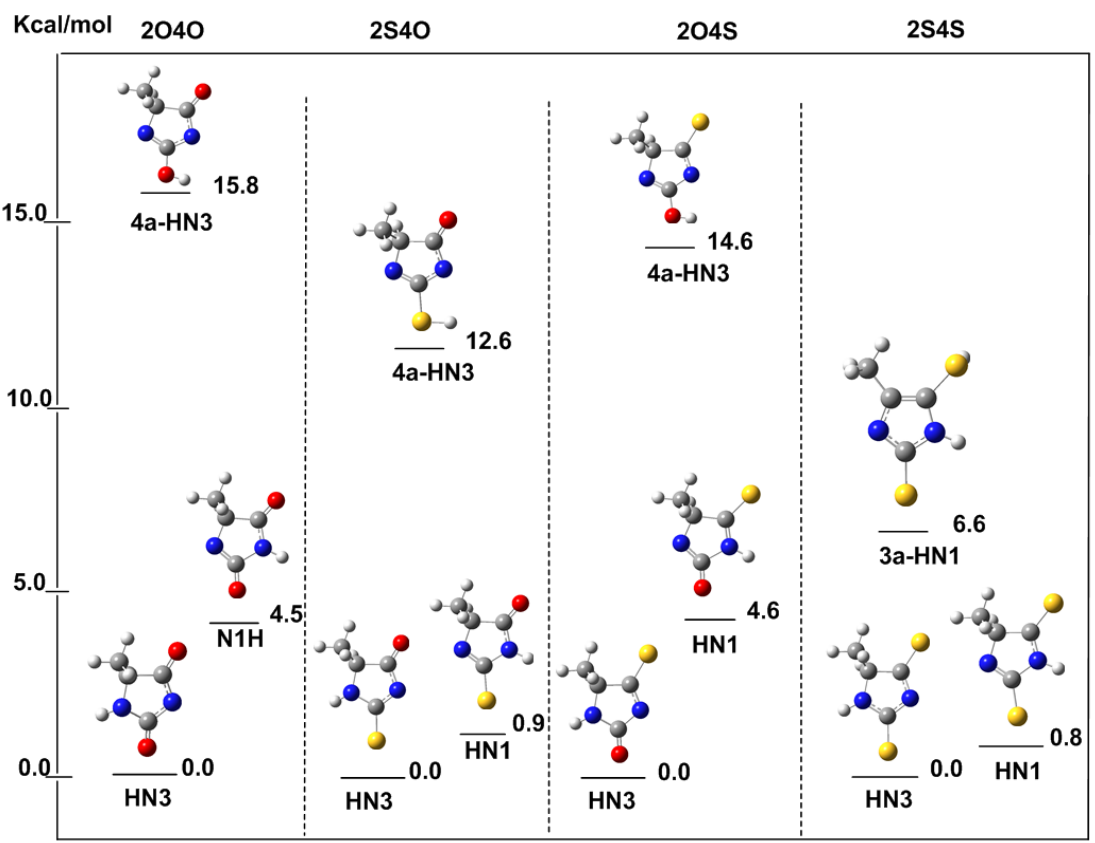

Figure 1. Relative stability of the most stable deprotonated forms of 5-methylhydantoin and its thio derivatives. All values are in kcal/mol.

Enthalpies were evaluated by considering the thermal corrections at $298.15 \mathrm{~K}$. The gas phase-acidity was defined as the enthalpy of deprotonation $\left(\Delta \mathrm{H}^{298}\right)$ for reaction (A) [7].

$\mathrm{AH}(\mathrm{g}) \rightarrow \mathrm{A}^{-}(\mathrm{g})+\mathrm{H}^{+}(\mathrm{g})$

The enthalpy of deprotonation, $\Delta \mathrm{H}^{298}$, was computed using equations 1 and 2 ,

$\Delta \mathrm{H}^{298}=\Delta \mathrm{E}^{298}+\Delta(\mathrm{pV})$
$\Delta \mathrm{E}^{298}=\left[\mathrm{E}^{298}\left(\mathrm{~A}^{-}\right)+3 / 2 \mathrm{RT}\right]-\mathrm{E}^{298}(\mathrm{AH})$

where $\mathrm{E}^{298}$ stands for the total energies of the stable conformations of acids and their anions (including the thermal energy correction at $\mathrm{T}=298.15 \mathrm{~K}$ ). In equation 1 , we substituted $\Delta(\mathrm{pV})=\mathrm{RT}$ [one mole of gas is obtained in the reaction (A)]. Notice that there is an inverse relationship between the magnitude of the $\Delta \mathrm{H}^{298}$ and the strength of the acid. The larger the value of the $\Delta H^{298}$, the weaker is the acid [7].

\section{Results and discussion}

The structures of all different species that can be envisaged from deprotonation and tautomerization of the compounds under investigation are presented in Scheme 1. Thus, the first two structures in Scheme 1, HN1 and HN3, correspond to the anions derived from the elimination of the imide protons $\mathrm{N} 1-\mathrm{H}$ and $\mathrm{N} 3-\mathrm{H}$, respectively, while the remaining species are tautomers that produced by a 1,3-proton migration. All structures that are listed are minima on potential energy surface, PES. The full set of data (total energies, ZPE corrections, thermal corrections to energies (TCE) and thermal corrections to enthalpies (TCH)) for all tautomers in Scheme 1 are given in Table 1-4 of the Supporting Information. The relative energies of the two anions, HN1 and HN3, which are derived from the deprotonation of 5-methylhydantoin and its thio derivatives and the first most stable enolic structures are shown in Figure 1. The relative energies and enthalpies of these and the remaining tautomers in Scheme 1 are reported in Table 5 , together with information on the transition states connecting the most stable conformers in each case.

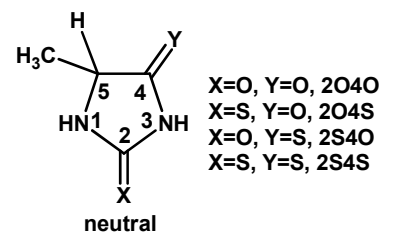



HN1<smiles>[Y]C1=NC([Y])C(C)([Hg])N1</smiles>

1a-HN1

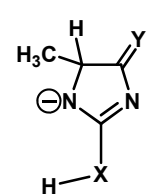

1b-HN1

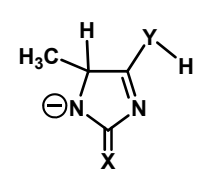

2a-HN1<smiles>[X]C1NC([R])C([Y])N1</smiles>

HN3
2b-HN1<smiles></smiles>

3a-HN1<smiles>[X]c1[nH]c([O-])c(C)c1[Y]</smiles>

3b-HN1<smiles>[Y]C1=N[C@@H](C)C(=O)N1</smiles>

4a-HN3<smiles>[Y]C1=NC([Y])C([Y])=N1</smiles>

4b-HN3<smiles>[Y]C1=C(C)[C@H]([Y])NC1=O</smiles>

5a-HN3<smiles></smiles>

5b-HN3

Scheme 1 
Table 1. The total energies in atomic units at B3LYP/6-311+G(d,p) (E1) B3LYP/6-311+G(2df,2p)//6-311+G(d,p) (E2), zero-point energy (ZPE), thermal correction to energy (TCE), thermal correction to enthalpy (TCH) of the $\mathbf{2 0 4 0}$ molecule. All values are in Hartree.

\begin{tabular}{lllll}
\hline Species & E1 & E2 & ZPE & TCE \\
\hline Neutral & -416.161560 & -416.1855910 & 0.108153 & 0.115528 \\
HN1 & -415.596786 & -415.6197440 & 0.094269 & 0.101247 \\
HN3 & -415.604876 & -415.6279560 & 0.094840 & 0.101672 \\
1a-HN1 & -415.579553 & -415.6026830 & 0.094751 & 0.101640 \\
1b-HN1 & -415.578788 & -415.6019300 & 0.094791 & 0.101639 \\
2a-HN1 & -415.556466 & -415.5794640 & 0.093859 & 0.100855 \\
2b-HN1 & -415.548904 & -415.5725680 & 0.102191 \\
3a-HN1 & -415.548605 & -415.5722840 & 0.093335 & 0.100451 \\
3b-HN1 & -415.548605 & -415.5722840 & 0.092950 & 0.100492 \\
4a-HN3 & -415.579553 & -415.6026840 & 0.092952 & 0.100494 \\
4b-HN3 & -415.578788 & -415.6019290 & 0.094751 & 0.101639 \\
5a-HN3 & -415.561657 & -415.5853950 & 0.094790 & 0.101637 \\
5b-HN3 & -415.552378 & -415.5767140 & 0.093493 & 0.100979 \\
TS3(HN1-3a-HN1) & -415.4833816 & -415.5066209 & 0.093145 & 0.101438 \\
TS2(HN3-5a-HN3) & -415.4911592 & -415.5145564 & 0.088102 & 0.102583 \\
TS3(HN3-HN1) & -415.4761668 & -415.4986933 & 0.088568 & 0.095452 \\
TS1(HN1-1a-HN1) & -415.5286788 & -415.5519821 & 0.095305 \\
TS2(HN1-2a-HN1) & -415.5021294 & -415.5256775 & 0.088738 & 0.01923 \\
TS1(HN3-4a-HN3) & -415.5259848 & -415.5494008 & 0.089368 & 0.095473 \\
\end{tabular}

Table 2. The total energies in atomic units at B3LYP/6-311+G(d,p) (E1) B3LYP/6-311+G(2df,2p)//6-311+G(d,p) (E2), zero-point energy (ZPE), thermal correction to energy (TCE), thermal correction to enthalpy (TCH) of the $\mathbf{2 S 4 0}$ molecule. All values are in Hartree.

\begin{tabular}{|c|c|c|c|c|c|}
\hline Species & E1 & E2 & ZPE & TCE & TCH \\
\hline Neutral & -739.115711 & -739.1405330 & 0.105919 & 0.113616 & 0.114560 \\
\hline HN1 & -738.567280 & -738.5906630 & 0.092559 & 0.099902 & 0.100847 \\
\hline HN3 & -738.568630 & -738.5921120 & 0.092571 & 0.099870 & 0.100814 \\
\hline 1a-HN1 & -738.540920 & -738.5650810 & 0.088736 & 0.096417 & 0.097362 \\
\hline 1b-HN1 & -738.540844 & -738.5650570 & 0.088830 & 0.096437 & 0.097381 \\
\hline 2a-HN1 & -738.524820 & -738.5480440 & 0.092085 & 0.099443 & 0.100387 \\
\hline 2b-HN1 & -738.516135 & -738.5400770 & 0.091522 & 0.099020 & 0.099964 \\
\hline 3a-HN1 & -738.527882 & -738.5523850 & 0.091282 & 0.099415 & 0.100359 \\
\hline 3b-HN1 & -738.527882 & -738.5523850 & 0.091282 & 0.099415 & 0.100360 \\
\hline 4a-HN3 & -738.540920 & -738.5650800 & 0.088733 & 0.096416 & 0.097361 \\
\hline $4 b-H N 3$ & -738.540844 & -738.5650570 & 0.088828 & 0.096436 & 0.097380 \\
\hline $5 \mathrm{a}-\mathrm{HN} 3$ & -738.540340 & -738.5647640 & 0.091755 & 0.099831 & 0.100776 \\
\hline $5 b-H N 3$ & -738.530258 & -738.5554920 & 0.090885 & 0.099413 & 0.100357 \\
\hline TS1(HN3-4a-HN3) & -738.503264 & -738.5271504 & 0.085796 & 0.093020 & 0.093964 \\
\hline TS2(HN3-5a-HN3) & -738.455048 & -738.4790078 & 0.086372 & 0.093603 & 0.094547 \\
\hline TS3(HN3-HN1) & -738.429890 & -738.4528700 & 0.085855 & 0.093033 & 0.093977 \\
\hline TS4(HN1-1a-HN1) & -738.508102 & -738.5318740 & 0.086092 & 0.093253 & 0.094197 \\
\hline TS5(HN1-2a-HN1) & -738.468998 & -738.4928810 & 0.086879 & 0.094083 & 0.095027 \\
\hline TS6(HN1-3a-HN1) & -738.497638 & -738.5211670 & 0.086966 & 0.094222 & 0.095167 \\
\hline
\end{tabular}

Table 3. The total energies in atomic units at B3LYP/6-311+G(d,p) (E1) B3LYP/6-311+G(2df,2p)//6-311+G(d,p) (E2), zero-point energy (ZPE), thermal correction to energy (TCE), thermal correction to enthalpy (TCH) of the 204S molecule. All values are in Hartree.

\begin{tabular}{|c|c|c|c|c|c|}
\hline Species & E1 & E2 & ZPE & TCE & TCH \\
\hline Neutral & -739.116632 & -739.14118 & 0.105908 & 0.113659 & 0.114603 \\
\hline HN1 & -738.563080 & -738.58637 & 0.092365 & 0.099641 & 0.100585 \\
\hline HN3 & -738.571030 & -738.59434 & 0.092729 & 0.099982 & 0.100927 \\
\hline 1a-HN1 & -738.547970 & -738.57128 & 0.092828 & 0.100061 & 0.101006 \\
\hline 1b-HN1 & -738.546550 & -738.56984 & 0.092827 & 0.100042 & 0.100986 \\
\hline 2a-HN1 & -738.520230 & -738.54435 & 0.087893 & 0.095661 & 0.096605 \\
\hline 2b-HN1 & -738.519030 & -738.54371 & 0.087785 & 0.095610 & 0.096555 \\
\hline 3a-HN1 & -738.536200 & -738.56278 & 0.088196 & 0.096198 & 0.097142 \\
\hline 3b-HN1 & -738.536200 & -738.56278 & 0.088198 & 0.096198 & 0.097142 \\
\hline $4 a-H N 3$ & -738.547970 & -738.57128 & 0.092827 & 0.100060 & 0.101004 \\
\hline $4 b-H N 3$ & -738.546550 & -738.56984 & 0.092833 & 0.100047 & 0.100991 \\
\hline $5 a-H N 3$ & -738.531590 & -738.55775 & 0.087723 & 0.096006 & 0.096950 \\
\hline $5 b-H N 3$ & -738.531590 & -738.55775 & 0.087722 & 0.096006 & 0.096950 \\
\hline TS1(HN3-4a-HN3) & -738.489180 & -738.51285 & 0.087067 & 0.094276 & 0.095220 \\
\hline TS2(HN3-5a-HN3) & -738.475280 & -738.49936 & 0.085157 & 0.092605 & 0.093550 \\
\hline TS3(HN3-HN1) & -738.440200 & -738.46296 & 0.086364 & 0.093462 & 0.094406 \\
\hline TS4(HN1-1a-HN1) & -738.494780 & -738.51836 & 0.087459 & 0.094493 & 0.095437 \\
\hline TS5(HN1-2a-HN1) & -738.483310 & -738.50714 & 0.085454 & 0.092705 & 0.093650 \\
\hline TS6(HN1-3a-HN1) & -738.513760 & -738.53725 & 0.087958 & 0.095125 & 0.096070 \\
\hline
\end{tabular}

\subsection{Relative stabilities and catalytic effects of deprotonation process}

As mentioned above, oxo- and thiohydantoin derivatives present different tautomers that can be generated through appropriate hydrogen shifts. Therefore, in order to rationalize their intrinsic reactivity, we must establish which tautomer is predominant in the gas phase. Recently, we have shown, in neutral [17] and protonated [18] molecules, that the dioxo tautomers in the case of 2,4-dioxohydantoin and the oxothione or the dithione tautomer in the case of thiohydantoin are the most stable. It was also found that the energy barriers connecting different neutral tautomers are very high. Therefore, the aforementioned tautomers, if the molecule is not excited, will be the only ones present in the gas phase.

Our first result, to be noted, deduced from the relative energy calculations listed in Table 5 and shown in Figure 1, is that in general, in all cases, the most stable deprotonated structure corresponds to the anion HN3, which produced by the direct elimination of the imide proton $\mathrm{N} 3-\mathrm{H}$. 
Table 4. The total energies in atomic units at B3LYP/6-311+G(d,p) (E1) B3LYP/6-311+G(2df,2p)//6-311+G(d,p) (E2), zero-point energy (ZPE), thermal correction to energy (TCE), thermal correction to enthalpy (TCH) of the $\mathbf{2 S} \mathbf{S} \mathbf{S}$ molecule. All values are in Hartree.

\begin{tabular}{|c|c|c|c|c|c|}
\hline Species & E1 & E2 & ZPE & TCE & TCH \\
\hline Neutral & -1062.071259 & -1062.096568 & 0.103742 & 0.111765 & 0.112709 \\
\hline HN1 & -1061.531903 & -1061.555677 & 0.090629 & 0.098273 & 0.099217 \\
\hline HN3 & -1061.532566 & -1061.556352 & 0.090253 & 0.098049 & 0.098993 \\
\hline 1a-HN1 & -1061.509142 & -1061.533454 & 0.086779 & 0.094816 & 0.095760 \\
\hline 1b-HN1 & -1061.508605 & -1061.532977 & 0.086891 & 0.094854 & 0.095798 \\
\hline 2a-HN1 & -1061.487869 & -1061.512225 & 0.086167 & 0.094254 & 0.095198 \\
\hline 2b-HN1 & -1061.486115 & -1061.511082 & 0.085957 & 0.094164 & 0.095108 \\
\hline 3a-HN1 & -1061.512344 & -1061.539316 & 0.086580 & 0.095051 & 0.095996 \\
\hline 3b-HN1 & -1061.512344 & -1061.539315 & 0.086580 & 0.095052 & 0.095996 \\
\hline 4a-HN3 & -1061.509142 & -1061.533455 & 0.086779 & 0.094817 & 0.095761 \\
\hline $4 b-H N 3$ & -1061.508605 & -1061.532976 & 0.086891 & 0.094854 & 0.095798 \\
\hline 5a-HN3 & -1061.509724 & -1061.536140 & 0.086579 & 0.095083 & 0.096027 \\
\hline $5 b-H N 3$ & -1061.509724 & -1061.536139 & 0.086582 & 0.095083 & 0.096027 \\
\hline TS1(HN3-4a-HN3) & -1061.466864 & -1061.490962 & 0.083851 & 0.091416 & 0.092360 \\
\hline TS2(HN3-5a-HN3) & -1061.441384 & -1061.465937 & 0.083376 & 0.091127 & 0.092071 \\
\hline TS3(HN3-HN1) & -1061.393450 & -1061.416640 & 0.083356 & 0.090950 & 0.091894 \\
\hline TS4(HN1-1a-HN1) & -1061.474460 & -1061.498560 & 0.084123 & 0.091620 & 0.092564 \\
\hline TS5(HN1-2a-HN1) & -1061.452251 & -1061.477171 & 0.084003 & 0.092031 & 0.092975 \\
\hline TS6(HN1-3a-HN1) & -1061.452251 & -1061.477171 & 0.084003 & 0.092031 & 0.092975 \\
\hline
\end{tabular}

Table 5. Relative energies and enthalpies of the deprotonated tautomers and rotaomers of 5-methyldynatoin and its thio derivatives in gas phase. All values are given in $\mathrm{kcal} / \mathrm{mol}$.

\begin{tabular}{|c|c|c|c|c|c|c|c|c|}
\hline \multirow{2}{*}{ Species } & \multicolumn{2}{|c|}{2040} & \multicolumn{2}{|c|}{$2 S 40$} & \multicolumn{2}{|c|}{$204 S$} & \multicolumn{2}{|c|}{$2 S 4 S$} \\
\hline & $\Delta \mathbf{E}$ & $\Delta \mathbf{H}$ & $\Delta \mathbf{E}$ & $\Delta \mathbf{H}$ & $\Delta \mathbf{E}$ & $\Delta \mathbf{H}$ & $\Delta \mathbf{E}$ & $\Delta \mathbf{H}$ \\
\hline$\overline{\mathrm{HN} 1}$ & 4.5 & 4.9 & 0.9 & 0.9 & 4.6 & 4.8 & 0.8 & 0.6 \\
\hline HN3 & 0.0 & 0.0 & 0.0 & 0.0 & 0.0 & 0.0 & 0.0 & 0.0 \\
\hline 1a-HN1 & 15.8 & 15.8 & 12.5 & 14.8 & 14.6 & 14.5 & 10.2 & 12.4 \\
\hline 1b-HN1 & 16.3 & 16.3 & 12.6 & 14.9 & 15.5 & 15.4 & 10.6 & 12.7 \\
\hline 2a-HN1 & 29.3 & 29.9 & 27.1 & 27.4 & 25.7 & 28.7 & 22.8 & 25.4 \\
\hline 2b-HN1 & 33.1 & 34.0 & 31.5 & 32.1 & 26.0 & 29.1 & 23.4 & 26.0 \\
\hline 3a-HN1 & 33.1 & 34.2 & 23.9 & 24.7 & 14.7 & 17.5 & 6.6 & 8.9 \\
\hline 3b-HN1 & 33.1 & 34.2 & 23.9 & 24.7 & 14.7 & 17.5 & 6.6 & 8.9 \\
\hline 4a-HN3 & 15.8 & 15.8 & 12.5 & 14.8 & 14.6 & 14.5 & 10.2 & 12.4 \\
\hline 4b-HN3 & 16.3 & 16.3 & 12.6 & 14.9 & 15.5 & 15.4 & 10.6 & 12.7 \\
\hline 5a-HN3 & 25.5 & 26.3 & 16.6 & 17.2 & 17.4 & 20.5 & 8.6 & 10.9 \\
\hline 5b-HN3 & 30.5 & 31.6 & 21.7 & 22.7 & 17.4 & 20.5 & 8.6 & 10.9 \\
\hline TS1(HN3-4a-HN3) & 42.2 & 45.8 & 32.4 & 36.5 & 44.1 & 45.5 & 33.0 & 36.9 \\
\hline TS1(HN3-5a-HN3) & 63.4 & 67.3 & 63.3 & 67.1 & 50.4 & 55.1 & 48.2 & 52.5 \\
\hline TS3(HN3-HN1) & 73.5 & 77.3 & 79.0 & 83.2 & 74.5 & 78.4 & 79.1 & 83.3 \\
\hline TS4(HN1-1a-HN1) & 40.9 & 44.3 & 29.7 & 33.7 & 41.1 & 44.3 & 28.3 & 36.7 \\
\hline TS5(HN1-2a-HN1) & 56.6 & 60.4 & 55.2 & 58.7 & 45.8 & 50.2 & 41.1 & 46.0 \\
\hline TS6(HN1-3a-HN1) & 68.2 & 72.4 & 37.6 & 41.0 & 29.9 & 32.8 & 28.1 & 35.2 \\
\hline
\end{tabular}

In fact, isomer HN3 was found largely more stable in the cases 2040 and 2045 than isomer HN1 by about 4.5 and 4.6 $\mathrm{kcal} / \mathrm{mol}$,respectively. While this energy gap drops to 0.9 and $0.8 \mathrm{kcal} / \mathrm{mol}$,respectively, in the cases of $\mathbf{2 S 4 0}$ and $2 \mathrm{~S} 4 \mathrm{~S}$.

For 2040 compound, it was found that the relative stability trend of the most stable tautomers is as follow: HN3 > HN1 > 1a-HN1 $\approx 4 \mathrm{a}-\mathrm{HN} 3>$ 5a-HN3 > 2a-HN1 > 3a-HN1. It was also found that the first less stable enolic structures 1a-HN1 and 4a-HN3 are almost degenerate, which is similar to the results obtained in the case of the neutral [17] and the protonated species [18]. Therefore, our tabulated results show that forms 1a-HN1 and 4a-HN3 are estimated to be $15.8 \mathrm{kcal} / \mathrm{mol}$ less stable than the global minimum isomer HN3 (Table 5). For 2S40, 204S and 2S4S species, our results suggest that the most stable deprotonated species corresponds to the HN3 isomer (Table 5 and Figure 1). The relative stability trends of the most stable species are as follow:

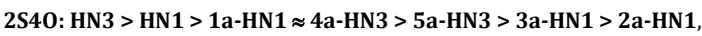

204S: HN3 > HN1 > 1a-HN1 $\approx$ 4a-HN3 > 3a-HN1 > 5a-HN3 > 2a-HN1, and

2S4S: HN3 > HN1 > 3a-HN1 > 5a-HN3 > 1a-HN1 $\approx$ 4a-HN3 > 2a-HN1,

For 2540 and $204 S$ compounds, the most stable enolic structures correspond to the 1a-HN1 and 4a-HN3 tautomers and they were found to be largely less stable by about 14.6 and $12.5 \mathrm{kcal} / \mathrm{mol}$, respectively, than the global minimum, HN3 isomer. The situation is completely different as far as the $\mathbf{2 S 4 S}$ species is concerned. The first stable enolic structure corresponds to form 3a-HN1, which can be produced starting from $\mathrm{HN1}$ isomer by a 1,-3 $\mathrm{H}$ migration from the $\mathrm{C} 5 \mathrm{H}$ group to the adjacent $\mathrm{C} 4=\mathrm{S}$ group. Our calculated results indicate that the enolic structure 3a-HN1 was found to be largely stable by bout 2.0 and $3.6 \mathrm{kcal} / \mathrm{mol}$, respectively, more stable than $5 \mathrm{a}-$ HN3 and 4a-HN3 forms, which can be produced by a suitable 1,3-H transfer starting from the global minimum, HN3 isomer.

In summary, the results reported for the 2040, 2540 and $204 \mathrm{~S}$ species suggest that the 1,3-H migration can take place at the heteroatom attached to $\mathrm{C} 2$ of the HN3 and HN1 isomer, regardless of the heteroatom type and the deprotonation site. Whereas, in the case of $\mathbf{2 S 4 S}$, the 1,3-H migration is favored at the sulfur atom attached to $\mathrm{C} 4$ of the HN1 isomer.

To study, which of the enolic structures can be observed in the gas phase, the transition states for 1,3- $\mathrm{H}$ migration have been calculated. Figure 2a-d shows schematic representation of the corresponding potential energy surface (PESs) of the tautomerization process of the species under investigation. The relative energies corresponding to the transition states, which connect the most stable deprotnated dioxo, dithio, and oxo/thio tautomers, HN3, with other species are listed in Table 5. As indicated above, tautomer HN3 is the global minimum in all cases, but there are significant similarities regarding the relative stability of the remaining tautomers.

On going from the global minimum, HN3 isomer, to the enolic forms, 4a-HN3 and 5a-HN3, two possible enolization mechanisms, TS1 and TS2, are proposed. The first mechanism (TS1) corresponds to the enolization of the oxo (or thione) groups attached to $\mathrm{C} 2$ by a $1,3-\mathrm{H}$ shift from the adjacent $\mathrm{N}-\mathrm{H}$ 

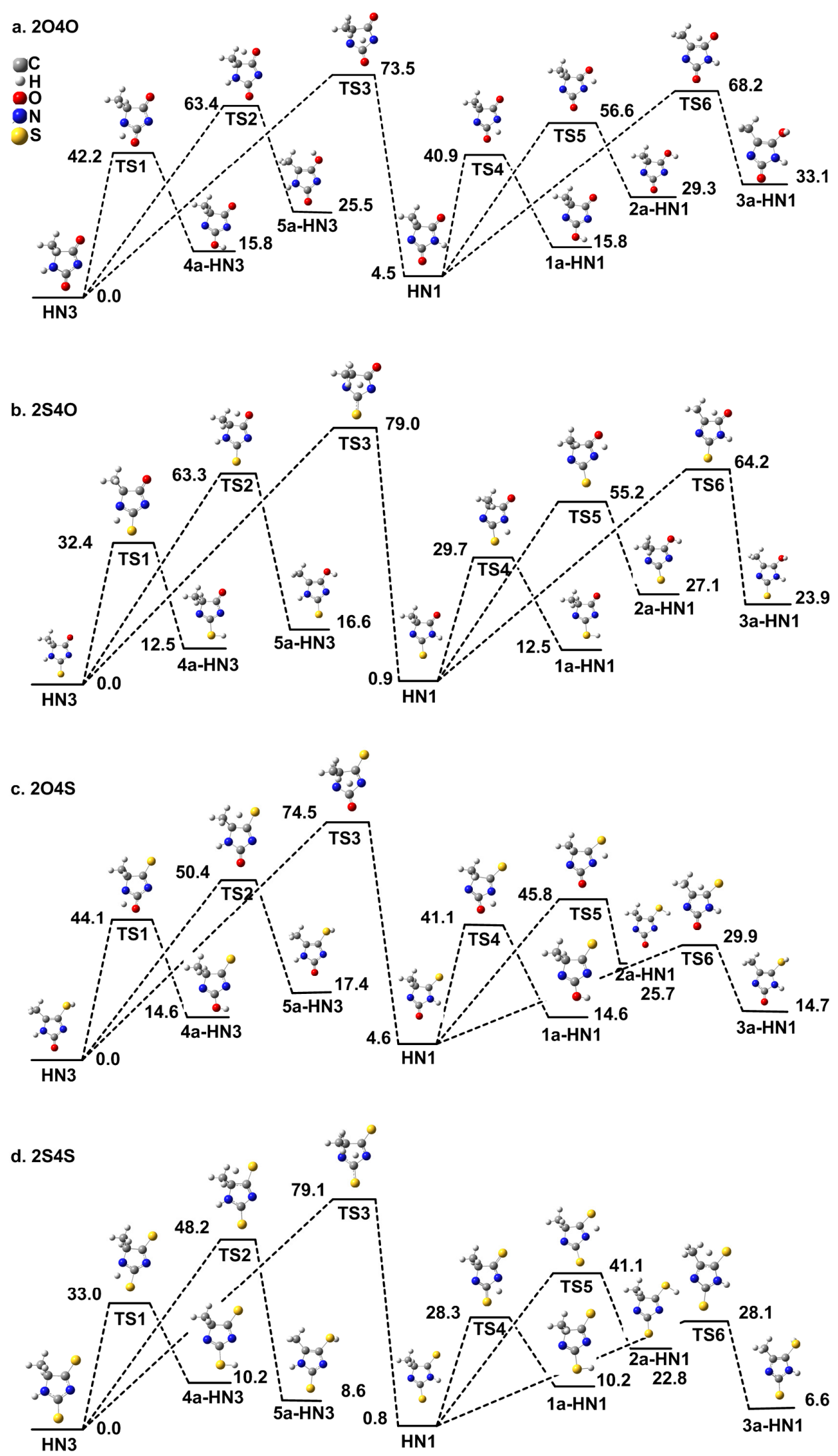

Figure 2. Energy profile of the unimolecular tautomerization processes of the deprotonated species (a) 2040, (b) 2S40, (c) 204S and (d) 2S4S. All values are in $\mathrm{kcal} / \mathrm{mol}$ 
Table 6. Calculated $298 \mathrm{~K}$ deprotonation energies, $\Delta \mathrm{H}^{298}$, of the 5-methylhydantoin and its thio derivatives at B3LYP with 6-311G(d,p) and 6-311+G(2df,2p)//$311+\mathrm{G}(\mathrm{d}, \mathrm{p})$ c. All values are in $\mathrm{kcal} / \mathrm{mol}$.

\begin{tabular}{|c|c|c|c|c|c|}
\hline \multirow{2}{*}{ Species } & \multirow{2}{*}{ Method } & \multicolumn{2}{|c|}{ Neutral } & \multicolumn{2}{|c|}{ Radical } \\
\hline & & N1 & N3 & N1 & N3 \\
\hline \multirow{2}{*}{2040} & B3LYPa & 356 & 351 & 201 & 196 \\
\hline & B3LYPb & 348 & 343 & 199 & 193 \\
\hline \multirow{2}{*}{$2 S 40$} & B3LYPa & 341 & 341 & 216 & 214 \\
\hline & B3LYPb & 338 & 337 & 221 & 219 \\
\hline \multirow{2}{*}{$204 S$} & B3LYPa & 346 & 335 & 220 & 214 \\
\hline & B3LYPb & 341 & 336 & 220 & 217 \\
\hline \multirow{2}{*}{$2 S 4 S$} & B3LYPa & 334 & 334 & 218 & 217 \\
\hline & B3LYPb & 333 & 332 & 226 & 222 \\
\hline
\end{tabular}

a B3LYP/6-311G(d,p).

b B3LYP/6-311+G(2df,2p)//6-311G(d,p).

c $\Delta \mathrm{H}^{298}=\Delta \mathrm{E}_{\mathrm{tot}}+\Delta \mathrm{ZPVE}+\Delta\left(\mathrm{H}^{298}-\mathrm{H}^{0}\right)+6.2 \mathrm{~kJ}$; scaled ZPVE by 0.9806 empirical factor.

group to yield form 4a-HN3, while the second mechanism (TS2) is accomplished by the enolization of the oxo (or thione) groups by a 1,3-H transfer from the adjacent $\mathrm{CH}$ group to yield species 5a-HN3. Our results indicate that for all compounds the first mechanism (TS1) is thermodynamically favored than the second one (TS2). Also importantly, the first enolization process (TS1) is more favorable when the heteroatom attached to $\mathrm{C} 2$ group is sulfur than that of the oxygen atom. For example, for compounds 2S40 and 2S4S transition barrier is estimated to be 32.4 and $33.0 \mathrm{kcal} / \mathrm{mol}$ above the minimum. Similarly, for compounds, $204 \mathrm{~S}$ and 2040 tautomerization barriers (TS1) are found to be 44.1 and $42.2 \mathrm{kcal} / \mathrm{mol}$, respectively, above the minimum. For compounds $204 S$ and $2 S 4 S$, the tautomerization barriers (TS2) are estimated to be 50.4 and $48.2 \mathrm{kcal} / \mathrm{mol}$, respectively, above the global minimum. Similarly, for compounds 2S40 and 2040 transition barriers (TS2) lies 63.8 and $63.4 \mathrm{kcal} / \mathrm{mol}$, respectively, above the global minimum. These results seem to be consistent with our previous studies $[17,18]$, in the sense that the oxo (or thione) group attached to $\mathrm{C} 2$ should be more basic than that attached to C4. Additionally, sulfur seems to be more basic than oxygen. Also, the enoliztion process of sulfur atom is thermodynamically favored than the oxygen one.

The same conclusion can also be reached if we follow the formation of the enolic structures starting from the second most stable isomer, HN1. For example, for all compounds the formation of 1a-HN1 is thermodynamically more favored than 2a-HN1. It is also worth mention that the formation of 1a-HN1 and 2a-HN3 can be produced by enoliztion of the oxo (or thione) groups attached to $\mathrm{C} 2$ and $\mathrm{C} 4$ by a $1,3-\mathrm{H}$ shift from the $\mathrm{N} 3-\mathrm{H}$. The enolization mechanism of the oxo (or thione) groups attached to $\mathrm{C} 2$ can be proceed either by a 1,3-H shift from the N3-H group to yield species $1 \mathrm{a}-\mathrm{HN} 1$ or by a $1,3-\mathrm{H}$ shift from the N1-H group to yield structure 4a-HN3. Although, our results indicate that the two tautomers are degenerate, the first mechanism is thermodynamically favored than the second one. Also importantly, these mechanisms are thermodynamically favored when the heteroatom attached to C2 is sulfur in all cases. These findings can be well explained as follow:,in compounds $2 S 40$ and $2 S 4 S$, on going from HN3 or HN1 to either 4a-HN3 or 1a-HN1 a C=S and a N-H bonds are replaced by a $\mathrm{C}=\mathrm{N}$ and a $\mathrm{S}-\mathrm{H}$ bonds, respectively, while for compounds $204 \mathrm{~S}$ and 2040 one replaces a $\mathrm{C}=\mathrm{O}$ and a $\mathrm{N}-\mathrm{H}$ bonds by a $\mathrm{C}=\mathrm{N}$ and a $\mathrm{O}-\mathrm{H}$ bonds. However an $\mathrm{S}-\mathrm{H}$ bond is weaker than a $\mathrm{N}-\mathrm{H}$ linkage, a $\mathrm{C}=\mathrm{N}$ bond is significantly stronger than a $\mathrm{C}=\mathrm{S}$ one, so that the overall enolization process is more favorable for $\mathbf{2 S 4 0}$ and 2S4S than for compounds $204 S$ and 2040. On the other hand, when these results are compared with those obtained for the neutral [17] and the protonated [18] species, in compound 2040 the activation barriers of the enolization process was found to be 12.7 and $7.9 \mathrm{kcal} / \mathrm{mol}$ lower than those obtained for the neutral[17] and protonated [18] species, respectively.

In summary, in what concerns the tautomer stability, the most important conclusion is that for $\mathbf{2 S 4 0}$ and $204 \mathrm{~S}$ the most stable tautomer is the oxo-thione form. Similarly, for 2S2S and 2040 compounds the dithione and the dioxo forms, respectively, are the most stable ones. On the other hand, as shown in Figure 2, the energy barriers connecting the different tautomers are very high, and therefore we can safely conclude that only the aforementioned tautomers will exist in the gas phase.

\subsection{Gas-phase acidity}

In Table 6 we have summarized the calculated acidities for the neutral 5-methylhydantoin and its thio derivatives. These values were obtained from DFT calculations using the B3LYP functional at $6-311 G(d, p)$ and $6-311+G(2 d f, 2 p) / / 6-311+G(d, p)$ basis functions. For sake of comparison we included the acidity of the radical molecule at the same basis functions. The full set of data (total energies, ZPE corrections, TCE and TCH) for all species under investigation are given in Tables 7 and 8 of the Supporting Information. The analysis of the data listed in Table 6 indicates that the values obtained from the $6-311 \mathrm{G}(\mathrm{d}, \mathrm{p})$ basis function are more than $8 \mathrm{kcal} / \mathrm{mol}$ higher than those obtained using $6-311+G(2 f d, 2 p) / / 6-311+G(d, p)$ one. This suggests that diffuse functions are required to lower the computed deprotonation energies of anions $[5,6,28]$.

As it is found in literature [29,30], data reported in Table 6 indicates that the most acidic site of 5-methylhydantoin and its thio derivatives is the N3-H group. It is noticed that, there is an inverse relationship between the magnitude of the $\Delta \mathrm{H}^{298}$ and the strength of the acid. The larger the value of the $\Delta \mathrm{H}^{298}$, the weaker is the acid. For $\mathbf{2 0 4 0}$ and $\mathbf{2 0 4 S}$, it is found that the acidity difference between $\mathrm{N} 3$ and $\mathrm{N} 1$ atoms is quite substantial and amounts to about $5.0 \mathrm{kcal} / \mathrm{mol}$ in favor of the former. Whereas, for $\mathbf{2 S 4 0}$ and $\mathbf{2 S 4 S}$ species, this acidity difference decreases to about $1.0 \mathrm{kcal} / \mathrm{mol}$. The reason for this behavior is probably due to the high polarizability and size of the sulfur atom attached to $\mathrm{C} 2$ over the oxygen, which allows a delocalization of the negative charge at both atoms. Our results suggest that the gas phase acidity trend of the molecules under investigation is as follow: 2S4S $>2$ S40 $>2040>2040$, which agrees with those reported experimentally [29]. Experimental data [30] showed that 2-thiohydantoin (pka=8.5) is slightly stronger acid than hydantoin (pka $=9.0$ ). From the results, we can deduce that both $\mathrm{NH}$ bonds are characterized by a weak acidity, which is sensibly lower than that of uracil and its thio derivatives $(320-333 \mathrm{kcal} / \mathrm{mol})[5,6]$ and higher than that of formamide $(359 \mathrm{kcal} / \mathrm{mol}), \quad N$-methylformamide $(\sim 361$ $\mathrm{kcal} / \mathrm{mol}$ ) or $N$-methylacetamide $(362 \mathrm{kcal} / \mathrm{mol}$ ) [31]. From the results obtained in this study, we can deduce that both $\mathrm{NH}$ bonds are characterized by a weak acidity, which is sensibly lower than that of uracil and its thio derivatives (320-333 $\mathrm{kcal} / \mathrm{mol}$ ) [5,6] and higher than that of formamide (359 $\mathrm{kcal} / \mathrm{mol}), \quad N$-methylformamide $(\sim 361 \mathrm{kcal} / \mathrm{mol})$ or $N$ methylacetamide (362 kcal/mol)[31]

In order to confirm our results concerning the acidity trend of the compounds under probe, an appropriate isodesmic reaction has been considered. Reactions 1 and 2 (Table 9) permit us to compare the relative stability of both HN1 and HN3 anions for the all the compounds. 
Table 7. B3LYP/6-311G(d,p) Optimized energies, E, zero-point energy, ZPE, thermal correction to energy, TCE, thermal correction to enthalpy, TCH, of the neutral and cationic Radicals of 2040, 2S40, 204S and 2S4S molecules. All values are in hartree.

\begin{tabular}{|c|c|c|c|c|}
\hline Species & $\mathbf{E}$ & ZPE & TCE & TCH \\
\hline \multicolumn{5}{|c|}{ 2040-neutral } \\
\hline Neutral & -416.1503667 & 0.108394 & 0.115724 & 0.116669 \\
\hline N1 & -415.5715871 & 0.094329 & 0.101299 & 0.102243 \\
\hline N3 & -415.5799112 & 0.094942 & 0.101742 & 0.102686 \\
\hline \multicolumn{5}{|c|}{ 2040-Radical } \\
\hline Neutral & -415.8013220 & 0.105860 & 0.113224 & 0.114169 \\
\hline N1 & -415.4713249 & 0.094462 & 0.1016 & 0.102544 \\
\hline N3 & -415.4713250 & 0.093280 & 0.100747 & 0.101691 \\
\hline \multicolumn{5}{|c|}{ 2S40-neutral } \\
\hline Neutral & -739.1077140 & 0.106177 & 0.113817 & 0.114761 \\
\hline N1 & -738.5522520 & 0.092733 & 0.100062 & 0.101007 \\
\hline N3 & -738.5524940 & 0.092668 & 0.099956 & 0.100900 \\
\hline \multicolumn{5}{|c|}{ 2S40-Radical } \\
\hline Neutral & -738.7950590 & 0.105653 & 0.113406 & 0.114350 \\
\hline N1 & -738.4399897 & 0.092255 & 0.099751 & 0.100695 \\
\hline N3 & -738.4287180 & 0.092291 & 0.099961 & 0.100905 \\
\hline \multicolumn{5}{|c|}{ 204S-neutral } \\
\hline Neutral & -739.108544 & 0.106138 & 0.113845 & 0.114789 \\
\hline N1 & -738.545945 & 0.092402 & 0.099697 & 0.100642 \\
\hline N3 & -738.555045 & 0.092996 & 0.100209 & 0.101154 \\
\hline \multicolumn{5}{|c|}{ 204S-radical } \\
\hline Neutral & -738.7916610 & 0.105486 & 0.113239 & 0.114183 \\
\hline N1 & -738.4306228 & 0.092319 & 0.099757 & 0.100702 \\
\hline N3 & -738.4327490 & 0.092511 & 0.10008 & 0.101024 \\
\hline \multicolumn{5}{|c|}{ 2S4S-neutral } \\
\hline Neutral & -1062.065926 & 0.103997 & 0.111957 & 0.112901 \\
\hline N1 & -1061.522989 & 0.090781 & 0.098411 & 0.099356 \\
\hline N3 & -1061.522866 & 0.090482 & 0.098242 & 0.099186 \\
\hline \multicolumn{5}{|c|}{ 2S4S-radical } \\
\hline Neutral & -1061.758258 & 0.103163 & 0.111128 & 0.112072 \\
\hline N1 & -1061.399692 & 0.090127 & 0.097925 & 0.098869 \\
\hline N3 & -1061.392742 & 0.089747 & 0.097600 & 0.098544 \\
\hline
\end{tabular}

Table 8. B3LYP/6-311+G(d,p) Optimized energies, E1, B3LYP/6-311+G(2df,2p)/6-311+G(d,p), single point energy, E2, zero-point energy, ZPE, thermal correction to energy, TCE, thermal correction to enthalpy, TCH, of the neutral and cationic radicals of 2040, 2S40, 204S and 2S4S molecules. All values are in hartree.

\begin{tabular}{|c|c|c|c|c|c|}
\hline Species & E1 & E2 & ZPE & TCE & TCH \\
\hline \multicolumn{6}{|c|}{ 2040-radical } \\
\hline Neutral & -415.8066260 & -415.8315030 & 0.105699 & 0.113085 & 0.114029 \\
\hline N1 & -415.4821725 & -415.5058033 & 0.094266 & 0.101435 & 0.102379 \\
\hline N3 & -415.4610542 & -415.4848640 & 0.093121 & 0.100618 & 0.101562 \\
\hline \multicolumn{6}{|c|}{ 2S40-radical } \\
\hline Neutral & -738.8012690 & -738.8278380 & 0.105454 & 0.113250 & 0.114195 \\
\hline N1 & -738.4494504 & -738.4614016 & 0.092133 & 0.099645 & 0.100589 \\
\hline N3 & -738.4391405 & -738.4639790 & 0.092315 & 0.099969 & 0.100913 \\
\hline \multicolumn{6}{|c|}{ 204S-radical } \\
\hline Neutral & -738.7975870 & -738.8240070 & 0.105340 & 0.113118 & 0.114062 \\
\hline N1 & -738.4386779 & -738.4628818 & 0.092125 & 0.099597 & 0.100541 \\
\hline N3 & -738.4430888 & -738.4676920 & 0.092466 & 0.100049 & 0.100993 \\
\hline \multicolumn{6}{|c|}{ 2S4S-radical } \\
\hline Neutral & -1061.763577 & -1061.790435 & 0.102948 & 0.110960 & 0.111904 \\
\hline N1 & -1061.406195 & -1061.419329 & 0.089998 & 0.097814 & 0.098758 \\
\hline N3 & -1061.400349 & -1061.425133 & 0.089574 & 0.097463 & 0.098407 \\
\hline
\end{tabular}

Table 9. Relative stability of both HN1 and HN3 anions by using an appropriate Isodesmic reaction

\begin{tabular}{|c|c|c|c|c|c|}
\hline \multirow{2}{*}{ Species } & \multirow{2}{*}{ Reaction } & \multicolumn{4}{|c|}{$\Delta \mathrm{E}, \mathrm{kcal} / \mathrm{mol}$} \\
\hline & & 2040 & $2 S 40$ & $204 S$ & $2 S 4 S$ \\
\hline (1) HN1 -isomer & $\mathrm{H}_{3} \mathrm{C}$ & -67.6 & -77.0 & -74.2 & -82.3 \\
\hline (2) HN3- isomer & $\mathrm{H}_{3} \mathrm{C}$ & -72.2 & -77.9 & -78.7 & -83.1 \\
\hline
\end{tabular}

The first conspicuous fact is that both reactions 1 and 2 are endothermic, which indicates that both HN1 and HN3 isomers are stabilized upon deprotonation. It was found that the stabilization energy is greater for the HN3 isomer than the HN1 isomer, indicating that the $\mathrm{N} 3-\mathrm{H}$ group is more acidic than the
N1-H (Table 9). The results presented in chart 1 show that the deprotonated anions in the case of the $\mathbf{2 S 4 S}$ compound are the most stable anions among all the species under probe. Therefore, the relative stability trend might be arranged as 
follow: 2S4S > 204S > $2240>$ 2040, in agreement with our previous arrangement based on the deprotonation energies.

As it has been shown above, the most acidic site of the neutral 5-methylhydantoin and it thio derivatives is the $\mathrm{N} 3-\mathrm{H}$ group. Our results for the neutral radicals indicate that this is also the case in all cases. It is worth to mention that the radical cations have been obtained by ionization of the neutral molecules and then by deprotonation of the acidic sites in the ionized structures (Scheme 2). Our results show some significant changes, however, as far as the acidity of their radical cations is concerned. As should be expected, the 5methylhydantoin and thiohydantoin radical cations are more acidic than the corresponding neutrals, but still in all of them the N3-H group remains as the most acidic site, although the gap with respect to the N1-H acidity is rather small for the particular case of $2 \mathrm{~S} 4 \mathrm{~S}$ and $2 \mathrm{~S} 4 \mathrm{O}$. It is found that the acidity values of the radical molecules are higher than those of the corresponding neutrals. Our tabulated results (Table 6) indicate that the acidity difference is ranging from 107 to 150 $\mathrm{kcal} / \mathrm{mol}$ in favor of the radical cations.

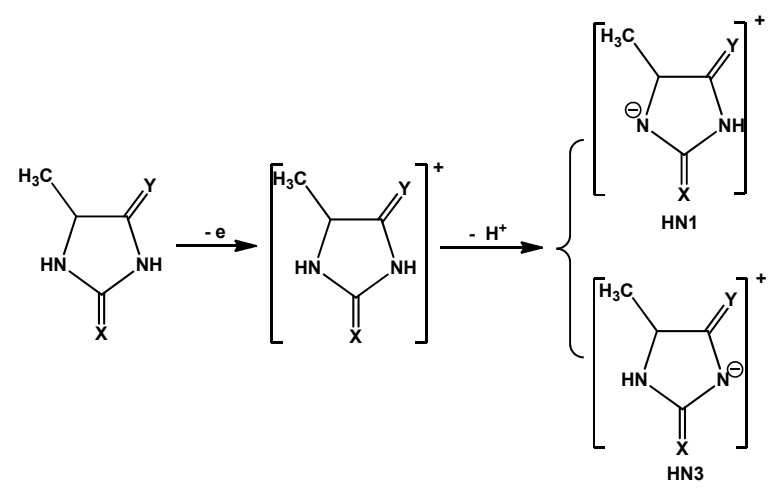

Scheme 2

\section{Conclusions}

Similar to what was found previouly in protonation processes, the diketo, dithio, keto/thio and thio/keto isomers of the 5-methylhydantoin thio derivatives remain the most stable structures. It has been shown that, in all cases, HN3 isomers were found to be more stable than the HN1 ones. For 2040, 2540 and $204 \mathrm{~S}$ compounds, the $1,3-\mathrm{H}$ transfer is favored at the heteroatom attached to $\mathrm{C} 2$, regardless of its type. Whereas, for $\mathbf{2 S 4 S}$ compound the 1,3-H transfer is favored at the sulfur atom attached to C4. The barriers for proton migration between different tautomers are rather large. Our results showed that the ring-nitrogen atom at position 3 (N3) is more acidic than that at position 1 (N1), hence the 5methylhydantoin and its thio derivatives are an N3-acid. Among all the considered molecules, the 2S4S molecule was found to be the most acidic one. It has been found that the two $\mathrm{N}-\mathrm{H}$ bonds in the 5-methylhydantoin and its thio derivatives are characterized by a weak acidity.

\section{Acknowledgements}

The Author gratefully acknowledges Prof. Dr. Gernot Frenking and Dr. Ponnadurai Ramasami for their useful comments. A generous allocation of computational time at the Scientific Computational Center (CCC) of the Universidad Autonoma de Madrid and Philipps-Universität Marburg also acknowledged.

\section{References}

[1]. Smith, B. J.; Radom, L. J. Am. Chem. Soc. 1992, 114, 36-41.

[2]. Smith, B. J.; Radom, L. J. Am. Chem. Soc. 1993, 115, 4885-4888.
[3]. Whittleton, S. R.; Hunter, K. C.; Wetmore, S. D. J. Phys. Chem. A 2004, 108, 7709-7718.

[4]. Nohodchi, A.; Bolourtchian, N.; Dinarvand, R. Int. J. Pharm. 2003, 250, 85-97.

[5]. Nguyen, M. T.; Chandra, A. K.; Zeegers-Huyskens, T. J. Chem. Soc., Faraday Trans. 1998, 94, 1277-1280.

[6]. Lamsabhi, M.; Alcami, M.; Mo, O.; Yanez, M. J. Phys. Chem. A 2006, 110 1943-1950.

[7]. Remko, M.; Lyne, P. D.; Richards, W. G. Phys. Chem. Chem. Phys. 1999, 1, 5353-5357.

[8]. Lamsabhi, M.; Alcami, M.; Mo, O.; Bouab, W.; Esseffar, M.; Abboud, J. L. -M.; Yanez, M. J. Phys. Chem. A 2000, 104, 5122-5130.

[9]. Mo, O.; De Paz, J. L. G.; Yanez, M. J. Phys. Chem. 1986, 90, 5597-5604.

[10]. Dang, P.; Madan, A. K. J. Chem. Inf. Comput. Sci. 1994, 34, 1162-1166.

[11]. Klainpeter, E. Struct. Chem. 1997, 8, 161-165.

[12]. Klainpeter, E.; Heydenreich, M.; Kalder, L.; Koch, A.; Henning, D. Kempter, G.; Benassi, R.; Taddei, F. J. Mol. Struct. 1997, 403, 111-122.

[13]. Camerman, K.; Camerman, N. Acta Cryst. B 1971, 27, 2205-2211.

[14]. Simig, G.; Lemport, K.; Tamas, J.; Czria, G. Tetrahedron 1975, 31, 11951200.

[15]. Yadav, A.; Yadav, V. K. J. Mol. Struct. (Theochem) 1994, 315, 245-251.

[16]. Yadav, A.; Yadav, V. K. J. Mol. Struct. (Theochem) 1994, 315, 245-251.

[17]. Schmidt, M. W.; Baldridge, K. K.; Boatz, J. A.; Jensen, J. H.; Koseki, S.; Gordon, M. S.; Nguyen, K. A.; Windus, T. L.; Albert, S. T. QCPE Bull. 1990, 10, 52-54.

[18]. Safi, Z. S.; Abu-Awwad, F. E-J. Chem. 2008, 5, 884-893.

[19]. Safi, Z. S.; Frenking, G. Int. J. Quantum Chem. 2012, In press, DOI: 10.1002/qua.24017.

[20]. Frisch, M. J.; Trucks, G. W.; Schlegel, H. B.; Scuseria, G. E.; Robb, M. A. Cheeseman, J. R.; Scalmani, G.; Barone, V.; Mennucci, B.; Petersson, G. A.; Nakatsuji, H.; Caricato, M.; Li, X.; Hratchian, H. P.; Izmaylov, A. F.; Bloino, J.; Zheng, G.; Sonnenberg, J. L.; Hada, M.; Ehara, M.; Toyota, K.; Fukuda, R.; Hasegawa, J.; Ishida, M.; Nakajima, T.; Honda, Y.; Kitao, O. Nakai, H.; Vreven, T.; Montgomery, Jr. , J. A.; Peralta, J. E.; Ogliaro, F.; Bearpark, M.; Heyd, J. J.; Brothers, E.; Kudin, K. N.; Staroverov, V. N.; Kobayashi, R.; Normand, J.; Raghavachari, K.; Rendell, A.; Burant, J. C.; Iyengar, S. S.; Tomasi, J.; Cossi, M.; Rega, N.; Millam, N. J.; Klene, M.; Knox, J. E.; Cross, J. B.; Bakken, V.; Adamo, C.; Jaramillo, J.; Gomperts, R.; Stratmann, R. E.; Yazyev, O.; Austin, A. J.; Cammi, R.; Pomelli, C.; Ochterski, J. W.; Martin, R. L.; Morokuma, K.; Zakrzewski, V. G.; Voth, G. A.; Salvador, P.; Dannenberg, J. J.; Dapprich, S.; Daniels, A. D.; Farkas, Ö.; Foresman, J. B.; Ortiz, J. V.; Cioslowski, J.; Fox, D. J. Gaussian, Inc. , Wallingford CT, 2009.

[21]. Parr, R. G.; Yang, W. Density-Functional Theory of Atoms and Molecules, Oxford University Press, New York, 1994

[22]. Neumann, R.; Nobes, R. H.; Handy, N. C. Mol. Phys. 1996, 97, 1-36.

[23]. Becke, A. D. Phys. Rev. A 1988, 38, 3098-3100.

[24]. Becke, A. D. J. Chem. Phys. 1993, 98, 5648-5652.

[25]. Lee, C.; Yang, W.; Parr, R. G. Phys. Rev. B 1988, 37, 785-789.

[26]. Gill, P. M. W.; Johnson, B. G.; Pople, J. A.; Frisch, M. J. Chem. Phys. Lett. 1992, 197, 499-505.

[27]. Kapp J.; Remko, M.; Schleyer, P. v. P. J. Am. Chem. Soc. 1996, 118, 5745 5751.

[28]. Scott, A. P.; Radom, L. J. Phys. Chem. 1996, 100, 16502-16513.

[29]. Del Bene, J. E. J. Phys. Chem. 1993, 97, 107-110.

[30]. Puszynska-Tuszkanow, M.; Daszkiewicz, M.; Maciejewska, G.; Adach A.; Cieslak-Golonka, M. Struct. Chem. 2010, 21, 315-332.

[31]. Vendano, C.; Menendez, J. C. In Hydantoin and Its Derivatives. KirkOthmer's Encyclopedia of Chemical Technology, 2000, 13, 512-533.

[32]. Meot-Ner (Mautner), M. J. J. Am. Chem. Soc. 1988, 110, 3071-3075. 